\title{
PML as a Potential Predictive Factor of Oxaliplatin/ Fluoropyrimidine-Based First Line Chemotherapy Efficacy in Colorectal Cancer Patients
}

\author{
BRUNO VINCENZI,' DANIELE SANTINI,' GIUSEPPE PERRONE, ${ }^{2}$ FRANCESCO GRAZIANO, ${ }^{3}$ \\ FOTIOS LOUPAKIS, ${ }^{4}$ GAIA SCHIAVON, ${ }^{5}$ ANNA MARIA FREZZA, ${ }^{\prime}$ ANNA MARIA RUZZO, ${ }^{6}$ \\ SERGIO RIZZO, ${ }^{7}$ PIERFILIPPO CRUCITTI, ${ }^{8}$ SARA GALLUZZO,' ALICE ZOCCOLI,' \\ CARLA RABITTI, ${ }^{2}$ ANDREA ONETTI MUDA, ${ }^{2}$ ANTONIO RUSSO, ${ }^{7 *}$ ALFREDO FALCONE, ${ }^{4}$ \\ AND GIUSEPPE TONINI'
}

'Department of Oncology, University Campus Bio-Medico, Rome, Italy

${ }^{2}$ Department of Surgical Pathology, University Campus Bio-Medico, Rome, Italy

${ }^{3}$ Unit of Medical Oncology, Hospital of Pesaro, Italy

${ }^{4}$ Unit of Medical Oncology 2, Azienda-Ospedaliero Universitaria Pisana, Istituto Toscano, Tumori and Department of Oncology, Transplantes and New Technologies in Medicine, University of Pisa, Italy

${ }^{5}$ Department of Medical Oncology, Erasmus University Medical Center, Daniel den Hoed Cancer Center, Rotterdam,

The Netherlands

${ }^{6}$ Section of Biochemistry and Molecular Biology "G. Fornaini", Department of Biomolecular Sciences, University of Urbino, Italy

${ }^{7}$ Section of Medical Oncology, Department of Surgical and Oncological Sciences, Università di Palermo, Palermo, Italy

${ }^{8}$ Department of Surgery, University Campus Bio-Medico, Rome, Italy

PML regulates a wide range of pathways involved in tumorigenesis, such as apoptosis, which is also one of the main mechanisms through which oxaliplatin and fluoropyrimidine exert their antineoplastic activity. The present study aims to investigate PML expression as a predictive factor of oxaliplatin/fluoropyrimidine therapy efficacy. Seventy-four metastatic colorectal cancer patients who received oxaliplatin/floropyrimidine-based first line therapy have been included in this retrospective study. PML expression was assessed by immunohistochemistry. PML down-regulation was detected in 39 (52.7\%) patients (I4 complete and 25 partial PML loss). RR was significantly lower $(25.6 \%)$ in patients with PML down-regulation than in patients with preserved $P M L$ expression $(60 \%)(P=0.006)$. Median TTP was 5.5 months when PML was down-regulated versus II.9 months in case of preserved PML expression $(P<0.000 \mathrm{I})$. A statistical significant difference was also detected in OS (I 5.6 and 24.5 months, respectively, $P=0.003$ ). The impact of PML downregulation on TTP and OS was statistically significant also in a multivariate model. This study represents the first evidence of a possible correlation between PML protein expression and outcome of metastatic colorectal cancer patients treated with oxaliplatin/ fluoropyrimidine-based first line therapy.

J. Cell. Physiol. 227: 927-933, 2012. (C) 20II Wiley Periodicals, Inc.

The promyelocytic leukemia (PML) gene, located at $15 q 22$, consists of 9 exons which encode for alternatively spliced isoforms with both cytoplasmatic and nuclear localization. PML nuclear isoforms (PML I, II, III, IV, V, VI) are characterized by a nuclear location signal (NLS), coded by exon 6 , which is absent in the cytoplasmatic isoforms. The NLS allows PML localization in the nucleoplasm or into complex protein structures known as PML nuclear bodies (PML-NBs).

PML-NBs appear as ring-like structures composed by highly ordered PML multimers which, together with SI00 proteins, represent the only constitutive elements of nuclear bodies. This basic structure works as a platform on which many other proteins are transiently recruited (Jensen et al., 200 I; Shen et al., 2006; Weidtkamp-Peters et al., 2008). The importance of PML as tumor suppressor gene was postulated since its identification at the breakpoint of $\mathrm{t}(15 ; 17)$ translocation, which brings to the fusion protein PML/RAR $\alpha$ that characterizes
Conflict of interest: The authors declare no competing interests.

Contributions section: AMR, AOM carried out the molecular genetic studies, participated in the sequence alignment and drafted the article. GP, CR carried out the immunoassays. BV, DS, FL, FG and AMF participated in the design of the study and performed the statistical analysis. GT, AR, SG, AZ, AF and SR conceived the study, and participated in its design and coordination and helped to draft the article. All authors read and approved the final article.

*Correspondence to: Antonio Russo, Department of Surgical and Oncological Sciences, Section of Medical Oncology, Università di Palermo, Via del Vespro 127, 90127 Palermo, Italy. E-mail: lab-oncobiologia@usa.net

Received 3 March 201 I; Accepted 6 April 2011

Published online in Wiley Online Library (wileyonlinelibrary.com), 18 April 201 I. DOI: $10.1002 / j c p .22801$ 
promyelocytic acute leukemia. Thanks to the interaction with many different partners in the contest of PML-NBs, PML is able to regulate key pathways of tumorigenesis and to control basic cellular functions such as senescence (Chan et al., 1997;

Ferbeyre et al., 2000; Pearson et al., 2000; Mallette et al., 2004), apoptosis (Wang et al., 1998b; Zhong et al., 2000; Salomoni et al., 2005; Halazonetis et al., 2008), and protein synthesis (Culjkovic et al., 2007). Furthermore, a recent work by Bernardi et al. shows how PML regulates HIF $\alpha$ levels through the interaction with mTOR. In fact, HIF $\alpha$ levels seem to be higher in PML $-/-$ mice, with consequently increased neoangiogenesis and tumor vascularization (Bernardi et al., 2006).

Despite all the previous reported evidences, a few studies up to date evaluated the expression of PML gene in different neoplasms. In 2004, Gurrieri et al. assessed PML expression in human cancers of multiple histologic origins through microarrays. They detected a partial reduction or complete loss of PML expression in prostatic adenocarcinoma, colon adenocarcinoma, breast cancer, lung cancer, lymphoma, CNS tumors, and germ cells tumors (Gurrieri et al., 2004). Further studies have shown a decreased PML expression in breast cancer, gastric cancer, NSCLC, and invasive epithelial tumors (Koken et al., I 995; Gambacorta et al., I 996; Zhang et al., 2000; Lee et al., 2007).

Oxaliplatin is one of the most widely used and effective agents in the treatment of colorectal cancer. It is a third generation platinum drug whose two-steps activation leads to the production of reactive compounds (Jerremalm et al., 2003) that bound to DNA, constituting cross-links between two adjacent guanosine residues (stable adducts). Oxaliplatin ability of inducing DNA structural changes confers to the drug a cytotoxic and antineoplastic action. In the treatment of metastatic colorectal cancer (mCRC), oxaliplatin $\left(85 \mathrm{mg} / \mathrm{m}^{2}\right.$ every 2 weeks) is given in association with 5 -fluorouracil (FU) and folinic acid (FOLFOX) or with capecitabine (XELOX). FOLFOX regimen has been proven to be associated with a longer progression free survival (PFS) ( 9 vs. 6.2 months) and a better response rate (RR) $(50.7 \%$ vs. $22.3 \%)$ when compared with LV5FU2 regimen in patients affected by $\mathrm{mCRC}$. Although the difference in terms of overall survival (OS) does not reach a statistical significance (I6.2 vs. I 4.7 months), FOLFOX resulted to be significantly superior to IFL in terms of 5 -years OS $(9.8 \%$ vs. $3.7 \% ; P=0.04$ ) (de Gramont et al., 2000). Moreover, IFL regimen was previously shown to be associated with longer survival when compared with LV5FU2 alone (Saltz et al., 2000). Thus, there are currently strong evidences that FOLFOX improves survival when compared to fluoropyrimidines alone.

A study presented by Chan et al. (1997) analyzed PML expression by immunofluorescence staining in HeLa cells treated with ionizing radiation $(20 \mathrm{~Gy})$ and cisplatin $(6 \mu \mathrm{g} / \mathrm{ml})$, showing a 5-10-fold increase in PML expression. These data underline the key role played by PML in the cellular response to DNA damage. However, at the moment there are no preclinical or clinical studies demonstrating a direct link between PML and sensitivity/resistance to oxaliplatin.

Given the possible relationship between oxaliplatin mechanism of action and PML involvement in apoptosis, the aim of the present study was to assess PML immunohistochemical (IHC) expression in colorectal cancer and evaluate the value of PML down-regulation as a predictive factor of resistance to oxaliplatin-based therapy in $\mathrm{mCRC}$ patients.

\section{Patients and Methods}

The present study is retrospective, thus it was not designed in "a priori" model. Seventy-four consecutive ( 40 males and 34 females, median age 61 years) $\mathrm{mCRC}$ patients were included from January 2005 to December 2006. This cohort represents all the patients that started a first line treatment for $\mathrm{mCRC}$ in the Department of Medical Oncology at University Campus Bio-Medico of Rome, the Unit of Medical Oncology at Hospital of Pesaro, and the Unit of Medical Oncology 2, AziendaOspedaliero Universitaria Pisana, Istituto Toscano between January 2005 and December 2005. Inclusion criteria were only the availability of representative tumor blocks for IHC analysis.

All tumor samples were collected at the time of surgical resection with written informed consent. All patients received an oxaliplatin/fluoropyrimidine-based first line regimen for metastatic disease (FOLFOX IV and XELOX regimen in 22 and 52 patients, respectively) (Table I). The decision to treat each patient according to one of the two regimens was made according to the physician's personal decision. Treatment was continued until the occurrence of radiologic progression as defined by RECIST criteria or the occurrence of either unacceptable toxicity or death. There was no difference in terms of dose intensity between patients treated with FOLFOX IV and those treated with XELOX regimen (data not shown). Tumor response was evaluated every 8 weeks by appropriate imaging techniques (computed tomography or magnetic resonance imaging). Assessment was performed by the investigators on the basis of the response evaluation criteria in solid tumors (RECIST). All the radiological tumor responses were confirmed by an independent radiological review. The cut-off time for survival analysis was May 2009 and the median follow-up was 28 months.

\section{PML immunohistochemical analysis}

PML expression was evaluated through immunohistochemistry by three independent observers. Representative tumor blocks were sectioned at $3 \mu \mathrm{m}$ thickness for IHC studies.

Immunohistochemistry was carried out by the streptoavidinbiotin method. A mouse monoclonal antibody against PML protein (clone PG-M3, Santa Cruz Biotechnology, Inc., Santa Cruz, CA) was used at 1:50 dilution. This antibody has been previously used and validated by our group and by others (Falini

TABLE I. Baseline characteristics of the patients

\begin{tabular}{|c|c|}
\hline Patient's characteristics & Number of patients (\%) \\
\hline $\begin{array}{l}\text { Total number } \\
\text { Male/female }\end{array}$ & $\begin{array}{c}74(100 \%) \\
40 / 34(54 / 46 \%)\end{array}$ \\
\hline \multicolumn{2}{|l|}{ Age (years) } \\
\hline Median & 63 years \\
\hline Range & $29-78$ years \\
\hline \multicolumn{2}{|l|}{ Performance status (ECOG) } \\
\hline Median & I \\
\hline Range & $1-2$ \\
\hline \multicolumn{2}{|l|}{ Primary tumor site } \\
\hline Colon & $48(64.8 \%)$ \\
\hline Rectum & $26(35.1 \%)$ \\
\hline \multicolumn{2}{|l|}{ Tumor grade } \\
\hline G2 & $23(31.0 \%)$ \\
\hline G3 & $44(59.5 \%)$ \\
\hline G4 & $7(9.5 \%)$ \\
\hline \multicolumn{2}{|l|}{ No. of metastatic sites } \\
\hline 1 & $31(41.9 \%)$ \\
\hline 2 & $23(31.1 \%)$ \\
\hline$\geq 3$ & $20(27.0 \%)$ \\
\hline \multicolumn{2}{|l|}{ Sites of metastases } \\
\hline Liver & $42(56.7 \%)$ \\
\hline Lung & $25(33.8 \%)$ \\
\hline Lymph nodes & $27(36.5 \%)$ \\
\hline Local & $15(20.3 \%)$ \\
\hline Other & $26(35.1 \%)$ \\
\hline \multicolumn{2}{|l|}{ Prior adjuvant therapy } \\
\hline None & $25(33.8 \%)$ \\
\hline FU/LV (Mayo Clinic or De Gramont schedules) & $49(66.2 \%)$ \\
\hline \multicolumn{2}{|l|}{ First line regimen } \\
\hline XELOX & $52(70.3 \%)$ \\
\hline FOLFOX & $22(29.7 \%)$ \\
\hline
\end{tabular}


et al., 1997; Mallette et al., 2004; Vincenzi et al., 2009). DakoCytomation Labelled Streptavidin-Biotin2, Horseradish Peroxidase (LSAB2 System, HRP, Milan, Italy) system was utilized as staining kit. 3-3-Diaminobenzidine was used for color development and hematoxylin was used for counterstaining. Negative control slides processed without primary antibody were included for each staining. Slides were examined without knowledge of the corresponding clinico-pathological data. Immunostaining was considered positive if appropriate brown staining was seen in tumor cells. PML expression was defined by calculating the percentage of nuclear immunoreactive cells in a total of I 000 neoplastic cells.

\section{Scoring and quantification of the immunoreactivity}

PML protein expression patterns were divided into complete loss (nuclear immunoreactivity in $<10 \%$ of tumor cells), focal positivity (in $\geq 10 \%$ but $<50 \%$ ), and diffuse positivity (in $\geq 50 \%$ ), as previously reported by Lee et al. (2007). Agreement in IHC evaluation among the three observers was $>90 \%$ (Kappa value: $0.93 \mathrm{I}$ ). In cases of disagreement, a final score was determined by consensus after re-examination. We compared RR and TTP between patients with and without PML down-regulation.

\section{MSI status determination}

DNA extracted from each tumor was amplified by standard polymerase chain reaction using microsatellite markers defined during the 1998 National Cancer Institute Workshop on Microsatellite Instability: BAT25, BAT26, DI7S250, D5S346, ACTC, DI8S55, BAT40, DI0S197, BAT34c4, and MycL. In most cases, normal control tissue was obtained from a separate, non-tumor tissue block. When this was not possible, non-cancer control tissue was obtained by microdissection. Whenever necessary, microdissection was performed to enrich tumor specimens for cancer cells, ensuring a minimum of $60 \%$ tumor within the sample. Tumors were considered MSIhigh (MSI-H) if instability was identified at $\geq 50 \%$ of the loci screened, MSI-low (MSI-L) if at least one but $\leq 50 \%$ of the loci showed instability, and microsatellite stable (MSS) if all loci were stable. For analysis, MSI-L and MSS cases were combined (MSI$\mathrm{L} / \mathrm{S}$ ). A minimum of five successfully amplified loci were required for classification.

\section{Statistical analysis}

Time to progression (TTP) was calculated as the period from the date of starting treatment to the first observation of disease progression or death from any cause. The duration of response was defined as the period of time from initiation of treatment (in a patient responding to therapy) until radiological or symptomatic disease progression. OS was calculated as the period from the date of starting treatment until death from any cause or until the date of the last follow-up, at which point data were censored. TTP and OS were determined by Kaplan-Meier product-limit method (Kaplan and Meier, 1958). The other prognostic variables tested were: tumor grading, liver involvement, previous adjuvant chemotherapy, albumin, alkaline phosphatase, gamma-GT, lactate dehydrogenase (LDH), and basal carcinoembryonic antigen (CEA) levels.

Stratified permutation tests were carried out to explore the association between tumor response and PML expression. Moreover, the differences in terms of TTP and OS according to PML expression were evaluated by log-rank test. Finally, Cox proportional hazards model was applied to the multivariate survival analysis. Chi square test was used to test the association between PML expression and tumor RR. SPSS software (version 17.00, SPSS, Chicago, IL) was used for statistical analysis. A $P$ value of less than 0.05 was considered to indicate statistical significance.
Results

\section{PML expression}

In normal colon epithelium, PML displayed a diffuse nuclear staining pattern (Fig. IA). Moreover, endothelial cells and tumor-infiltrating lymphocytes were also strongly positive for PML expression in both normal and tumor tissues, thus serving as internal positive controls. In contrast, PML staining was frequently focally or completely lost in tumor specimens.

PML down-regulation (defined as either complete loss or focal expression) was detected in $39(52.7 \%)$ patients. In the remaining 35 patients PML tumor expression was preserved.

In particular, 14 (18.9\%) of the total 74 colon adenocarcinoma samples were classified as PML complete loss (Fig. IB), and 25 (33.7\%) samples as focal expression (Fig. IC). In the remaining $35(47.2 \%)$ tissue samples PML was diffusely expressed (Fig. ID).

\section{Correlation between PML expression and treatment efficacy}

Patients with PML down-regulation showed a RR of $25.6 \%$ versus $60.0 \%$ in patients with preserved PML expression $(P=0.006)$. Moreover, the tumor control rate, defined as the percentage of patients who had a best-response rating of complete response, resulted significantly lower in those patients with PML down-regulation ( $43.6 \%$ vs. $82.8 \%, P=0.00 \mathrm{I})$ (Table 2).

No difference was identified between patients with complete loss or partial PML down-regulation in terms of RR and tumor control rate.

The median TTP was 5.5 (95\%Cl: $2.78-7.43)$ months in patients with PML down-regulation and significantly longer in patients without PML reduced protein expression (I I.00 months, 95\% Cl: 6.56-14.90; $P<0.0001)$. Moreover, also in terms of duration of response, $\mathrm{PML}$ protein expression showed a statistically significant impact in our cohort. OS was significantly different between the two groups of patients (I 5.60 and 24.50 months, respectively, $P=0.003$ ). All these data are summarized in Table 3 and Kaplan-Meier plots are presented in Figure 2.

Notably, no differences in terms of efficacy measurements were detected between the group of patients treated with FOLFOX and XELOX regimen and no difference in terms of oxaliplatin dose-intensity was recorded according to PML down-regulation (data not shown).

Finally, we performed survival analysis using a multivariate model both for TTP and OS, by introducing all the clinical variables that showed a statistical significant impact on prognosis in univariate analysis.

As reported in Table 4, PML maintained a statistically significant impact on TTP $(P=0.008)$ and OS $(P=0.0 \mathrm{II})$ in multivariate analysis.

\section{MSI status determination}

MSI-H and MSI-L were observed in 19 (25.7\%) and I 5 (20.3\%) of the 74 primary tumors studied, respectively. For analysis, MSI-L and MSS cases were combined and compared with the remaining patients (with $M S I$ ) In our cohort MSI did not correlate with efficacy $(R R)(P=0.450)$ and did neither predicted TTP nor OS ( $P=0.95 \mathrm{I}$ and 0.121 , respectively).

\section{Discussion}

Although there are still some enigmatic aspects in PML biology, research in this field has moved forward in the last few years and produced evidences suggesting a PML tumor suppressive function in non-hematopoietic neoplasms (Trotman et al., 2006; Ferguson et al., 2007). 

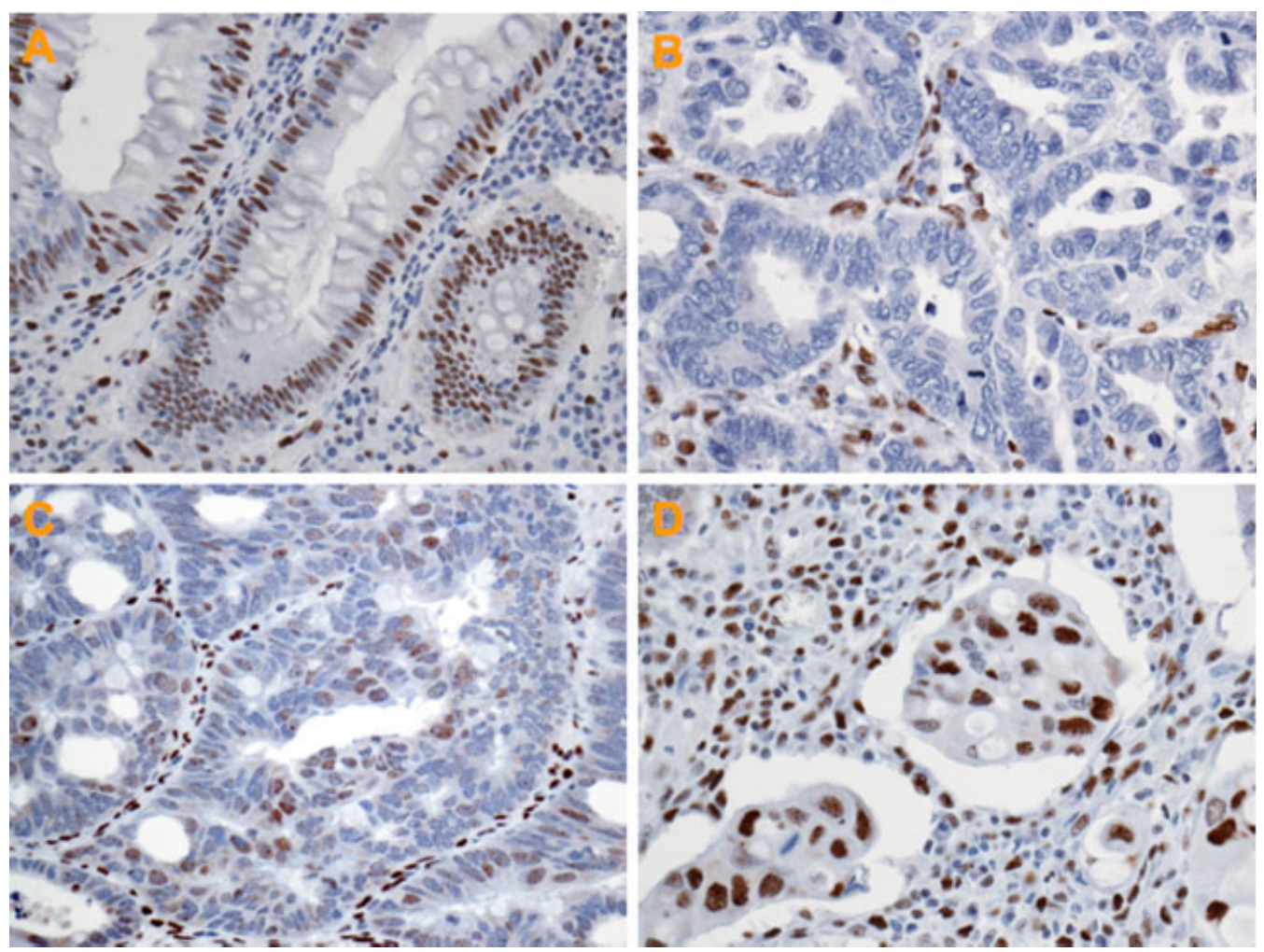

Fig. I. Promyelocytic leukemia (PML) protein detection by immunohistochemistry. (A) Positive PML immunostaining in peritumoral norma epithelial cells; (B) loss of PML protein expression in colon adenocarcinoma cells (nuclear immunoreactivity in <10\% of tumor cells); (C) focally expressed PML protein in colon adenocarcinoma cells (nuclear immunoreactivity in $\geq 10 \%$ but $<50 \%$ ); and (D) diffuse expression of PML protein in colon adenocarcinoma cells (nuclear immunoreactivity in $\geq \mathbf{5 0} \%$ ). In all images, nuclear PML staining in endothelial cells and tissue-associated lymphocytes represents positive control. Original magnification $400 \times$. [Color figure can be seen in the online version of this article, available at http://wileyonlinelibrary.com/journal/jcp]

Loss of PML expression is associated with transformation, progression or high tumor grade in some tumors and PML has been proven to be lost or down-regulated in many cancers of multiple histologic origins. For example, Gurrieri et al. found that PML gene is partially or completely lost in $31 \%$ and $17 \%$ of colon adenocarcinomas, respectively (Gurrieri et al., 2004). In our cohort (74 tissue samples), we observed preserved PML expression in $47.2 \%$ of cases and partial or complete PML loss in $52.7 \%$ of patients (18.9\% and $33.7 \%$, respectively).

PML has growth suppressive and pro-apoptotic properties and displays an altered expression pattern during human oncogenesis (Koken et al., 1995). Its increased expression suppresses the growth and tumorigenicity in cancer cells in vivo and PML deficient cells are resistant to apoptosis induced by multiple stimuli (He et al., 1997; Quignon et al., 1998; Wang et al., 1998a; Pearson et al., 2000; Wu et al., 2003). Apoptosis is also one of the main mechanisms through which platinum compounds, such as oxaliplatin, exert their antineoplastic activity.
Oxaliplatin is a third-generation platinum-containing drug, and oxaliplatin/fluoropyrimidine therapy has significantly improved efficacy compared with cisplatin-based regimens in the treatment of colorectal cancer. The combination of capecitabine and oxaliplatin is particularly attractive because of its favorable tolerability profile and efficacy. Furthermore, it has been shown that oral fluoropyrimidines are preferred by patients, obviating the drawbacks of prolonged intravenous infusion. Phase III trials comparing capecitabine/oxaliplatin with infusional regimens of $5-\mathrm{FU}+/-\mathrm{LV}$ and oxaliplatin in $\mathrm{mCRC}$ clearly point out how efficacy, in terms of median PFS and OS, and tolerability profile are similar between the two regimens as first and second line treatment (Cassidy et al., 2004; Cassidy et al., 2008; Rothenberg et al., 2008).

Different studies underline that oxaliplatin dose intensity is related both to efficacy and tolerability profile. Oxaliplatin dose intensification probably improves RR and PFS in pre-treated metastatic patients (dose below $85 \mathrm{mg} / \mathrm{m}^{2}$ may be associated with a worse outcome) with a slightly increased toxicity, mainly

TABLE 2. Radiological tumor response to oxaliplatin/fluoropyrimidine anticancer regimen according to PML protein expression

\begin{tabular}{lccr}
\hline & CR (\%) & PR (\%) & SD (\%) \\
\hline Down-regulated PML (39 pts) & - & $10(25.6 \%)$ & $7(17.9 \%)$ \\
Normally expressed PML (35 pts) & I (2.9\%) & $20(57.1 \%)$ & $22(56.5 \%)$ \\
\hline
\end{tabular}

$\mathrm{CR}$, complete response; $\mathrm{PR}$, partial response; $\mathrm{SD}$, stable disease; $\mathrm{PD}$, progressive disease. 
TABLE 3. Influence PML down-regulation on TTP, duration of response and OS

\begin{tabular}{lcc}
\hline & Median TTP $(95 \%$ C.I.) in months & $P$ value \\
\hline TTP & $5.50(95 \% \mathrm{Cl}: 2.78-7.43)$ & $<0.000$ I \\
$\quad$ Down-regulated PML & II.00 (95\%Cl: 6.56-14.90) & \\
$\quad$ Normally expressed PML & $2.8(95 \% \mathrm{Cl}:$ I.50-6.90) & 0.006 \\
$\begin{array}{l}\text { Duration of response } \\
\text { Down-regulated PML }\end{array}$ & $6.5(95 \% \mathrm{Cl}: 4.40-9-20)$ & \\
$\quad$ Normally expressed PML & $15.60(95 \% \mathrm{Cl}: 11.30-19.50)$ & 0.003 \\
OS & $24.50(95 \% \mathrm{Cl}: 21.00-28.60)$ & \\
$\quad$ Down-regulated PML &
\end{tabular}

neuropathy (Maindrault-Goebel et al., 2000, 200I). In the OPTIMOXI study (Tournigand et al., 2006), the first study evaluating the stop-start treatment strategy, previously untreated patients were randomly assigned to receive FOLFOX4 until progression or FOLFOX7 (oxaliplatin $130 \mathrm{mg} /$ $\mathrm{mq}$ ) for six cycles, then maintenance without oxaliplatin for 12 cycles, and reintroduction of FOLFOX7. RR was $58.5 \%$ in arm $A$ and $59.2 \%$ in arm B. Grade 3 sensory neuropathy was observed in $17.9 \%$ of the patients in arm $A$ versus $13.3 \%$ of patients in arm B. On the contrary, in the OPTIMOX2 study (Andre et al., 2007) oxaliplatin was administered at $100 \mathrm{mg} / \mathrm{mq}$ with significantly lower incidence of grade 3 sensory neuropathy $(9.5 \%)$. It is noteworthy that oxaliplatin dose intensity was not different between the groups of patients treated with FOLOFX IV and XELOX regimen.

The identification of predictive factors of response to standard chemotherapy and immunotherapy in patients affected by colorectal cancer is today a matter of strong clinical interest. Recently, several studies pointed out how the presence of K-Ras mutations in MCRC abrogates the efficacy of anti-EGFR therapy (Lievre et al., 2006; De Roock et al., 2008), leading the European Medicine Agency to restrict its use to patients with wild-type K-Ras tumors. BRAF status, EGFR amplification and cytoplasmic expression of PTEN seem to be also associated with outcome in K-Ras wild-type patients treated with a cetuximab-based regimen and they are currently under evaluation as possible additional predictive factors (Laurent-Puig et al., 2009). On the contrary, there is no evidence that patients with $\mathrm{K}-\mathrm{Ras} / \mathrm{BRAF}$ mutated tumors are less likely to benefit from standard chemotherapy agents such as irinotecan and oxaliplatin (Richman et al., 2009). Recently, a possible link between up-regulation of the nucleotide excision
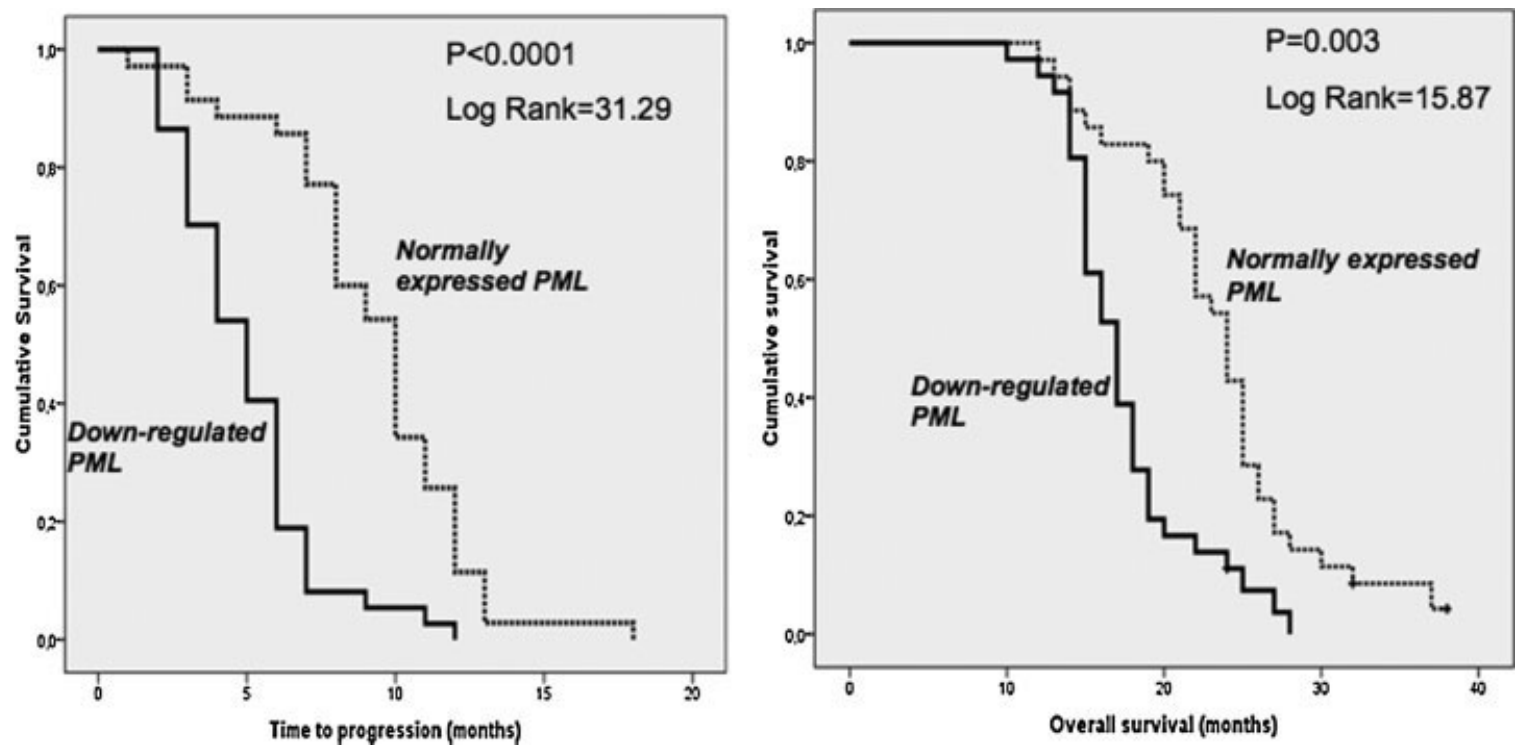

Fig. 2. Kaplan-Meier survival plots for PFS and OS in patients with normally expressed and down-regulated pml metastatic colorectal cancer treated with oxaliplatin/fluoropyrimidine-based first line chemotherapy.

TABLE 4. Multivariate analysis for PFS and OS

\begin{tabular}{|c|c|c|c|c|c|c|}
\hline \multirow[b]{2}{*}{ Factors } & \multicolumn{3}{|c|}{ Univariate } & \multicolumn{3}{|c|}{ Multivariate } \\
\hline & $\mathrm{RR}$ & $95 \% \mathrm{Cl}$ & $P$ & $\mathrm{RR}$ & $95 \% \mathrm{Cl}$ & $P$ \\
\hline \multicolumn{7}{|l|}{ Progression free survival } \\
\hline PS (ECOG) (70-80 vs. 90-100) & 1.56 & $1.23-1.85$ & 0.004 & 1.23 & $0.75-1.53$ & 0.120 \\
\hline Number of organs involved (I vs. more) & 0.77 & $0.37-0.95$ & 0.015 & 0.86 & $0.54-0.99$ & 0.048 \\
\hline PML down-regulation & 0.45 & $0.31-0.78$ & $<0.0001$ & 0.67 & $0.34-0.81$ & 0.008 \\
\hline \multicolumn{7}{|l|}{ Overall survival } \\
\hline PS (ECOG) $(70-80$ vs. $90-100)$ & 1.98 & $1.23-2.07$ & 0.002 & 1.56 & $1.18-1.99$ & 0.009 \\
\hline Carcinoembryonic antigen $^{\mathrm{a}}$ & 1.63 & $1.11-1.76$ & 0.001 & 1.02 & $0.89-1.13$ & 0.138 \\
\hline Number of organs involved (I vs. more) & 0.57 & $0.40-0.81$ & 0.002 & 0.72 & $0.66-0.89$ & 0.030 \\
\hline PML down-regulation & 0.63 & $0.34-0.88$ & 0.003 & 0.69 & $0.44-0.93$ & 0.011 \\
\hline
\end{tabular}

${ }^{a}$ Continuous variable for every 50 -point CEA increase. 
repair pathway and response to platinum-based therapy has been supposed. In colorectal cancer, single nucleotide polymorphism (SNP) at codon 188 of the ERCCI resulted associated with a reduced median survival, and it has been suggested as a possible predictor of clinical outcome in $\mathrm{mCRC}$ patients treated with platinum-based chemotherapy (Pare et al., 2008). Furthermore, gene polymorphisms of EGF (Spindler et al., 20I I), EGFR and its downstream effectors (such as IL-8) have been proposed to be associated with platinum compounds sensitivity in colorectal cancer. However, further studies are necessary to confirm these initial findings (Zhang et al., 2005).

The present study provides, for the first time, evidences suggesting a possible correlation between PML protein expression and outcome of $\mathrm{mCRC}$ patients treated with oxaliplatin/fluoropyrimidine-based first line therapy. The link between PML expression and efficacy of oxaliplatin/ fluoropyrimidine therapy has been evaluated through several clinical parameters such as TTP, duration of response and OS. A lower RR characterized patients with PML down-regulation (partial or complete loss) compared to those with preserved PML expression ( $25.6 \%$ vs. $60.0 \%$, respectively), without any significant difference between patients with complete loss or partial PML down-regulation. Patients with PML downregulation showed a significantly shorter median TTP than patients without reduced PML protein expression (5.5 vs. I I months). The difference in terms of OS rate appears extremely relevant, revealing a decreased OS time for patients with PML down-regulated expression. All the data regarding the impact of PML down-regulation on survival (TTP and OS) were confirmed also in multivariate analysis. In conclusion, this study seems to support the role played by PML in cellular response to DNA damage and the value of its down-expression as a factor predicting resistance to oxaliplatin/fluoropyrimidine therapy in mCRC.

Nevertheless, the significance of our study is limited by a small sample size, absence of a validation cohort, retrospective nature of the study itself and inability to determine prognostic versus predictive role of PML down-regulation. In order to confirm the value of our assumptions, further larger prospective studies appear mandatory. The identification of a predictive factor of resistance to oxaliplatin/fluoropyrimidine therapy, together with reliable markers of efficacy, would enable clinicians to quickly select patients most suitable for management by this strategy.

Finally, the evaluation of PML possible involvement in the pathogenesis of colorectal cancer (for example by assessing its expression in normal tissue, precancerous lesion and tumor samples) and the possible prognostic value of its downregulation would be of great interest.

\section{Literature cited}

Andre T, Tournigand C, Mineur L, Fellague-Chebra R, Flesch M, Mabro M, Hebbar M, Postel Vinay S, Bidard FC, Louvet C, de Gramont A. 2007. Phase Il study of an optimized 5fluorouracil-oxaliplatin strategy (OPTIMOX2) with celecoxib in metastatic colorectal cancer: A GERCOR study. Ann Oncol 18:77-8I.

Bernardi R, Guernah I, Jin D, Grisendi S, Alimonti A, Teruya-Feldstein J, Cordon-Cardo C Simon MC, Rafii S, Pandolfi PP. 2006. PML inhibits HIF-Ialpha translation and neoangiogenesis through repression of mTOR. Nature 442:779-785.

Cassidy J, Clarke S, Diaz-Rubio E, Scheithauer W, Figer A, Wong R, Koski S, Lichinitser M, Yang TS, Rivera F, Couture F, Sirzen F, Saltz L. 2008. Randomized phase III study of capecitabine plus oxaliplatin compared with fluorouracil/folinic acid plus oxaliplatin as firstline therapy for metastatic colorectal cancer. J Clin Oncol 26:2006-2012.

Cassidy J, Tabernero J, Twelves C, Brunet R, Butts C, Conroy T, Debraud F, Figer A, Grossmann J, Sawada N, Schoffski P, Sobrero A, Van Cutsem E, Diaz-Rubio E. 2004. XELOX (capecitabine plus oxaliplatin): Active first-line therapy for patients with metastatic colorectal cancer. J Clin Oncol 22:2084-2091.

Chan JY, Li L, Fan YH, Mu ZM, Zhang WW, Chang KS. 1997. Cell-cycle regulation of DNA damage-induced expression of the suppressor gene PML. Biochem Biophys Res Commun 240:640-646.

Culjkovic B, Topisirovic I, Borden KL. 2007. Controlling gene expression through RNA regulons: The role of the eukaryotic translation initiation factor elF4E. Cell Cycle 6:65-69. de Gramont A, Figer A, Seymour M, Homerin M, Hmissi A, Cassidy J, Boni C, Cortes-Funes H, Cervantes A, Freyer G, Papamichael D, Le Bail N, Louvet C, Hendler D, de Braud F, Wilson C, Morvan F, Bonetti A. 2000. Leucovorin and fluorouracil with or without oxaliplatin as first-line treatment in advanced colorectal cancer. J Clin Oncol 18:2938-2947.
De Roock W, Piessevaux H, De Schutter J, Janssens M, De Hertogh G, Personeni N, Biesmans B, Van Laethem JL, Peeters M, Humblet Y, Van Cutsem E, Tejpar S. 2008. KRAS wild-type state predicts survival and is associated to early radiological response in metastatic colorectal cancer treated with cetuximab. Ann Oncol 19:508-5/5.

Falini B, Flenghi L, Fagioli M, Lo Coco F, Cordone I, Diverio D, Pasqualucci L, Biondi A, Riganelli D, Orleth A, Liso A, Martelli MF, Pelicci PG, Pileri S. 1997. Immunocytochemical diagnosis of acute promyelocytic leukemia (M3) with the monoclonal antibody PG-M3 (anti-PML). Blood 90:4046-4053

Ferbeyre G, de Stanchina E, Querido E, Baptiste N, Prives C, Lowe SW. 2000. PML is induced by oncogenic ras and promotes premature senescence. Genes Dev 14:20152027.

Ferguson BJ, Dovey CL, Lilley K, Wyllie AH, Rich T. 2007. Nuclear phospholipase C gamma: Punctate distribution and association with the promyelocytic leukemia protein.J Proteome Res 6:2027-2032.

Gambacorta M, Flenghi L, Fagioli M, Pileri S, Leoncini L, Bigerna B, Pacini R, Tanci LN, Pasqualucci L, Ascani S, Mencarelli A, Liso A, Pelicci PG, Falini B. 1996. Heterogeneous nuclear expression of the promyelocytic leukemia (PML) protein in normal and neoplastic human tissues. Am J Pathol 149:2023-2035.

Gurrieri C, Capodieci P, Bernardi R, Scaglioni PP, Nafa K, Rush LJ, Verbel DA, Cordon-Cardo C, Pandolfi PP. 2004. Loss of the tumor suppressor PML in human cancers of multiple histologic origins. J Natl Cancer Inst 96:269-279.

Halazonetis TD, Gorgoulis VG, BartekJ. 2008. An oncogene-induced DNA damage model for cancer development. Science 319:1352-1355.

He D, Mu ZM, Le X, Hsieh JT, Pong RC, Chung LW, Chang KS. 1997. Adenovirus-mediated expression of PML suppresses growth and tumorigenicity of prostate cancer cells. Cancer Res 57:1868-1872.

Jensen K, Shiels C, Freemont PS. 200I. PML protein isoforms and the RBCC/TRIM motif Oncogene 20:7223-7233.

Jerremalm E, Eksborg S, Ehrsson H. 2003. Hydrolysis of oxaliplatin-evaluation of the acid dissociation constant for the oxalato monodentate complex. J Pharm Sci 92:436-438. Kaplan E, Meier P. 1958. Non parametric estimation from incomplete observations. J Am Stat Assoc 53:457-48I.

Koken MH, Linares-Cruz G, Quignon F, Viron A, Chelbi-Alix MK, Sobczak-Thepot J, Juhlin L, Degos L, Calvo F, de The H. 1995. The PML growth-suppressor has an altered expression in human oncogenesis. Oncogene 10:1315-1324.

Laurent-Puig P, Cayre A, Manceau G, Buc E, Bachet JB, Lecomte T, Rougier P, Lievre A, Land B, Boige V, Ducreux M, Ychou M, Bibeau F, Bouche O, Reid J, Stone S, Penault-Llorca F. 2009. Analysis of PTEN, BRAF, and EGFR status in determining benefit from cetuximab therapy in wild-type KRAS metastatic colon cancer. J Clin Oncol 27:5924-5930.

Lee HE, Jee CD, Kim MA, Lee HS, Lee YM, Lee BL, Kim WH. 2007. Loss of promyelocytic leukemia protein in human gastric cancers. Cancer Lett 247:103-109.

Lievre A, Bachet JB, Le Corre D, Boige V, Landi B, Emile JF, Cote JF, Tomasic G, Penna C Ducreux M, Rougier P, Penault-Llorca F, Laurent-Puig P. 2006. KRAS mutation status is predictive of response to cetuximab therapy in colorectal cancer. Cancer Res 66:39923995 .

Maindrault-Goebel F, de Gramont A, Louvet C, Andre T, Carola E, Gilles V, Lotz JP, Tournigand C, Mabro M, Molitor JL, Artru P, Izrael V, Krulik M. 2000. Evaluation of oxaliplatin dose intensity in bimonthly leucovorin and 48-hour 5 -fluorouracil continuous infusion regimens (FOLFOX) in pretreated metastatic colorectal cancer. Oncology Multidisciplinary Research Group (GERCOR). Ann Oncol I I:I477-I483.

Maindrault-Goebel F, de Gramont A, Louvet C, Andre T, Carola E, Mabro M, Artru P, Gilles V, Lotz JP, Izrael V, Krulik M. 200I. High-dose intensity oxaliplatin added to the simplified bimonthly leucovorin and 5 -fluorouracil regimen as second-line therapy for metastatic colorectal cancer (FOLFOX 7). Eur J Cancer 37:1000-1005.

Mallette FA, Goumard S, Gaumont-Leclerc MF, Moiseeva O, Ferbeyre G. 2004. Human fibroblasts require the $\mathrm{Rb}$ family of tumor suppressors, but not $\mathrm{p} 53$, for PML-induced senescence. Oncogene 23:91-99.

Pare L, Marcuello E, Altes A, del Rio E, Sedano L, Salazar J, Cortes A, Barnadas A, Baiget M. 2008. Pharmacogenetic prediction of clinical outcome in advanced colorectal cancer patients receiving oxaliplatin/5-fluorouracil as first-line chemotherapy. $\mathrm{Br} J$ Cancer 99:1050-1055.

Pearson M, Carbone R, Sebastiani C, Cioce M, Fagioli M, Saito S, Higashimoto Y, Appella E, Minucci S, Pandolfi PP, Pelicci PG. 2000. PML regulates $p 53$ acetylation and premature senescence induced by oncogenic Ras. Nature 406:207-210.

Quignon F, De Bels F, Koken M, Feunteun J, Ameisen JC, de The H. 1998. PML induces a novel caspase-independent death process. Nat Genet 20:259-265.

Richman SD, Seymour MT, Chambers P, Elliott F, Daly CL, Meade AM, Taylor G, Barrett JH, Quirke P. 2009. KRAS and BRAF mutations in advanced colorectal cancer are associate with poor prognosis but do not preclude benefit from oxaliplatin or irinotecan: Results from the MRC FOCUS trial. J Clin Oncol 27:593I-5937.

Rothenberg ML, Cox JV, Butts C, Navarro M, Bang Y], Goel R, Gollins S, Siu LL, Laguerre S, Cunningham D. 2008. Capecitabine plus oxaliplatin (XELOX) versus 5 -fluorouracil/folinic acid plus oxaliplatin (FOLFOX-4) as second-line therapy in metastatic colorectal cancer: A randomized phase III noninferiority study. Ann Oncol 19:1720-1726.

Salomoni P, Bernardi R, Bergmann S, Changou A, Tuttle S, Pandolfi PP. 2005. The promyelocytic leukemia protein PML regulates c-Jun function in response to DNA damage. Blood 105:3686-3690.

Saltz LB, Cox JV, Blanke C, Rosen LS, Fehrenbacher L, Moore MJ, Maroun JA, Ackland SP, Locker PK, Pirotta N, Elfring GL, Miller LL. 2000. Irinotecan plus fluorouracil and leucovorin for metastatic colorectal cancer. Irinotecan Study Group. N Engl J Med 343:905-9|4.

Shen TH, Lin HK, Scaglioni PP, Yung TM, Pandolfi PP. 2006. The mechanisms of PML-nuclear body formation. Mol Cell 24:331-339.

Spindler KL, Andersen RF, Jensen LH, Ploen J, Jakobsen A. 20I0. EGF6IA $>$ G polymorphism as predictive marker of clinical outcome to first-line capecitabine and oxaliplatin in metastatic colorectal cancer. Ann Oncol 21:535-539.

Tournigand C, Cervantes A, Figer A, Lledo G, Flesch M, Buyse M, Mineur L, Carola E, Etienne PL, Rivera F, Chirivella I, Perez-Staub N, Louvet C, Andre T, Tabah-Fisch I, de Gramont A 2006. OPTIMO XI: A randomized study of FOLFOX4 or FOLFOX7 with oxaliplatin in a stop- and-go fashion in advanced colorectal cancer - A GERCOR study. J Clin Oncol 24:394-400.

Trotman LC, Alimonti A, Scaglioni PP, Koutcher JA, Cordon-Cardo C, Pandolfi PP. 2006 Identification of a tumour suppressor network opposing nuclear Akt function. Nature 441:523-527.

Vincenzi B, Santini D, Perrone G, Russo A, Adamo V, Rizzo S, Castri F, Antinori A, Alloni R, Crucitti PF, Morini S, Rabitti C, Vecchio FM, Magistrelli P, Coppola R, Tonini G. 2009. Promyelocytic leukemia (PML) gene expression is a prognostic factor in ampullary cancer patients. Ann Oncol 20:78-83. 
Wang ZG, Delva L, Gaboli M, Rivi R, Giorgio M, Cordon-Cardo C, Grosveld F, Pandolfi PP. 1998a. Role of PML in cell growth and the retinoic acid pathway. Science 279:1547-155I. Wang ZG, Ruggero D, Ronchetti S, Zhong S, Gaboli M, Rivi R, Pandolfi PP. 1998b. PML is essential for multiple apoptotic pathways. Nat Genet 20:266-272.

Weidtkamp-Peters S, Lenser T, Negorev D, Gerstner N, Hofmann TG, Schwanitz G, Hoischen C, Maul G, Dittrich P, Hemmerich P. 2008. Dynamics of component exchange at PML nuclear bodies. J Cell Sci I21:2731-2743.

Wu WS, Xu ZX, Hittelman WN, Salomoni P, Pandolfi PP, Chang KS. 2003. Promyelocytic leukemia protein sensitizes tumor necrosis factor alpha-induced apoptosis by inhibiting the NF-kappaB survival pathway. J Biol Chem 278:12294-12304.
Zhang P, Chin W, Chow LT, Chan AS, Yim AP, Leung SF, Mok TS, Chang KS, Johnson PJ, Chan JY. 2000. Lack of expression for the suppressor PML in human small cell lung carcinoma. Int J Cancer 85:599-605

ZhangW StoehlmacherJ. Park DJ, Yang D BorchardE Gill, Tsao-Wei DD, Yun J, Gordon M Press OA, Rhodes K, Groshen S, Lenz H]. 2005. Gene polymorphisms of epidermal growth factor receptor and its downstream effector, interleukin-8, predict oxaliplatin efficacy in patients with advanced colorectal cancer. Clin Colorectal Cancer 5:I24-131.

Zhong S, Salomoni P, Ronchetti S, Guo A, Ruggero D, Pandolfi PP. 2000. Promyelocytic leukemia protein (PML) and Daxx participate in a novel nuclear pathway for apoptosis. J Exp Med 191:631-640. 